\title{
A.B. ПЕТУХOB
}

\section{ПРИСОЕДИНЕНИЕ КАЗАНСКОГО ХАНСТВА К РОССИИ В ОЦЕНКАХ АМЕРИКАНСКИХ ИСТОРИКОВ СЕРЕДИНЫ ХХ ВЕКА}

\begin{abstract}
Ключевые слова: американская историография истории России, Казанское ханство, московско-казанские отношения, политическая культура, государственная идеология, Э. Кинан, Я. Пеленски.
\end{abstract}

В статье подвергаются анализу взгляды американских историков середины XX в. на проблему присоединения Казанского ханства к России. Исследования по истории внешней политики России приобрели актуальность на Западе с началом «холодной войны», целью этих исследований была необходимость выявить исторические истоки «экспансионистской» внешней политики СССР и России. В поисках корней «русского экспансионизма» западная наука середины XX в. пришла к выводу о неевропейском характере российской государственности, византийских и монгольских истоках российской государственной идеологии, обосновавшей свои претензии на мировое господство. В трудах историков Гарвардского университета, специализировавшихся на истории России и стран Восточной Европы, была развита концепция двойственной природы внешнеполитической идеологии Российского государства в середине XVI в. C одной стороны, эта идеология была основана на монгольской политической традиции, унаследованной от Золотой Орды. С другой стороны, на российскую идеологию влияла и византийская политическая традиция. В работах Э. Кинана и Я. Пеленски присоединение Казанского ханства к России было представлено как первое воплощение на практике претензий московских правителей на господство на политическом пространстве Восточной Европы. Одновременно присоединение Казани стало мощным стимулом для фрормирования российской государственной идеологии, в основу которой легли исторические, династические, национальные и религиозные обоснования претензий на Казанское ханство. Поставленные в работах американских историков вопросы о российской политической культуре и идеологии XVI в., их отражении в источниках и трактовке идей современными исследователями сохраняют свою научную актуальность и сегодня.

В 1940-1950-е гг. в условиях «холодной войны» в странах Запада наблюдался рост интереса к России и российской истории. В теоретическом плане в центре внимания западных специалистов в это время находился вопрос о месте России в мире, это был своего рода поиск «особого пути» (Sonderweg) развития России, объяснения его отличия от пути исторического развития европейских стран. История России виделась как нечто уникальное и своеобразное.

Сложившиеся в этот период концепции происхождения российской государственности имели ряд общих черт. Во-первых, российская государственность рассматривалась как неевропейская, ее корни связывали с византийским или монгольским (восточным) внешним влиянием. Во-вторых, XVI век признавался важнейшим этапом в процессе формирования Российского го- 
сударства, именно тогда «Московия» впервые вышла на мировую арену. В-третьих, из неевропейской природы российской государственности выводился тезис об извечной «агрессивности» внешней политики России. В качестве примеров подобных трактовок российской истории можно привести работу А. Тойнби о роли византийского наследия в истории России [9] и концепцию «восточной деспотии» К. Витфогеля [10], связавшую российскую государственность с монгольской политической традицией.

Первая концепция указывала, что Москва, унаследовавшая византийские представления о государстве, стала воспринимать себя в XVI в. как «Третий Рим». Из доктрины православного русского мессианства якобы и выросли агрессивная экспансионистская политика российских правителей (русских царей и императоров, а потом и советских вождей) и их стремление к мировому господству. С точки зрения концепции «восточной деспотии» неограниченная власть московских правителей, ставших в XVI в. подражателями и продолжателями традиций монгольских ханов, позволяла им добиваться мирового господства как продолжения своей внутренней власти. Концентрация политической власти порождала неограниченную внешнюю экспансию. Отсюда вытекали постоянство российской внешней политики и мировое господство как ее конечная цель.

Одним из первых в зарубежной историографии вопрос о византийском и монгольском влиянии на политическую историю России XVI в. в 1950-е гг. поставил М. Чернявский, работавший в Великобритании [3]. В своей работе посвященной развитию русской политической мысли в XV-XVI вB., он отметил нелегкое совмещение монгольских и византийских политических представлений. Образы византийского басилевса и монгольского хана, которые пытались примерять на себе московские правители, существовали в российской политической традиции по отдельности. Как отмечает М. Чернявский, «если образ басилевса предназначался для благочестивого православного правителя, ведущего свой христианский народ к спасению, то образ хана, вероятно, сохранялся в идее русского правителя как образ покорителя России и ее народа, ни перед кем не несущего ответственности» [3. С. 475-476]. Двойственность политической природы Российского государства олицетворяют, по Чернявскому, сама личность Ивана IV и его противоречивые поступки [2].

На рубеже 1960-1970-х гг. внешняя политика Российского государства XVI в. на восточном направлении, в частности присоединение к России Казанского и Астраханского ханств, стала объектом внимания американских историков-славистов, связанных с Гарвардским центром русских исследований (сегодня Davis Center for Russian and Eurasian Studies), основанным в 1948 г. Среди них в первую очередь следует назвать Эдварда Кинана, видного американского специалиста по истории русского средневековья, в центре внимания которого находились проблемы политической истории России. В 1967 г. в журнале "Slavic Review" вышла его статья «Московия и Казань: некоторые вводные замечания к модели степной дипломатии», в которой Кинан изложил свой взгляд на проблему взаимоотношений двух государств [4].

В данной статье американский историк указал на нехватку дошедших до нас свидетельств по истории отношений Российского государства с татарскими ханствами. Так, например, источники, исходящие из Казанского ханства, практически отсутствуют. Поэтому исследователи вынуждены интерпретировать отношения Москвы и Казани, опираясь почти исключительно 
на данные московских летописей. Кинан считает такие интерпретации неудовлетворительными [4. С. 549]. Взамен американский историк предложил свою трактовку отношений Российского государства и Казанского ханства, опирающуюся на черты изучаемых культур (русской и татарской), анализ их политических институтов и традиций. Заметим, что проблема интерпретации московско-татарских отношений в XV-XVI вв. остается актуальной и сегодня, о чем свидетельствует дискуссия между российскими специалистами по истории средневековых татарских государств [1].

Применительно к внешней политике России XVI в. важен тезис Кинана о неоднородности московской политической культуры. Американский историк выделяет в ее составе два слоя, представленных духовенством и дипломатами. «Эти две культуры, - указывает Кинан, - так различались одна от другой, что они часто предлагали два различных и противоречащих между собой потока свидетельств» [4. С. 550]. Культура духовенства оставила свой след в виде летописей. Поскольку летописи должны были служить целям «московской пропаганды», Кинан описывает их как ненадежный источник. С его точки зрения, они конъюнктурны, очень искаженно описывают отношения Российского государства с его восточными соседями [4. С. 549]. Культура московских дипломатов оставила после себя другую группу источников, памятники дипломатических отношений России и соседних татарских государств. Они приоткрывают мир дипломатической культуры XV-XVI вв. Как пишет американский исследователь, «они открывают новый мир информации, отражающий не только международные отношения, но также культуру и характер властных институтов татарских государств» [4. С. 550]. Именно эта группа источников помогает более правильно, по Кинану, понять политику татарских ханств и Московии. Исходя из таких представлений о политической культуре Российского государства и соседних татарских государств, Кинан выстраивает свою модель «степной дипломатии». В ее рамках он и рассматривает взаимоотношения Российского государства и Казанского ханства в XV-XVI вв. По сути, Российское государство видится ему как одно из тех государств, которые образовались на пространстве Золотой Орды в процессе ее распада. Эта генетическая связь России с постордынскими государствами определила характер отношений между ними в рассматриваемый период.

Московские дипломаты и их коллеги в татарских ханствах придерживались одинаковых норм и правил, которые сложились в Золотой Орде. Эта ордынская школа «степной дипломатии», через которую прошли московские князья, позволяла им говорить со своими татарскими партнерами на одном дипломатическом языке, хорошо их понимать и чувствовать. Неудивительно, что, как пишет Кинан, отношения между двумя сторонами были прагматичными и, как правило, дружественными [4. С. 549]. Военные столкновения происходили, но они не имели характера межэтнического или межконфессионального конфликта. Отношения между Москвой и ее соседями не отличались принципиально от отношений татарских ханств друг с другом.

Такой взгляд Кинана на московскую политическую культуру и взаимоотношения Российского государства и Казанского ханства вызвал критические замечания и спровоцировал дискуссию на страницах «Slavic Review», участниками которой стали гарвардские историки И. Шевченко, О. Прицак, Я. Пеленски $[4,5,8]$. 
В рамках этой дискуссии О. Прицак сделал вывод о двойственности внешней политики России XV-XVI вв. «Официальная политика великого князя московского в отношении так называемых татар, - пишет он, - была основана, как подчеркивает Кинан, на прагматизме, без каких-либо национальных или религиозных чувств, в противоположность политике московской митрополии, которая теперь стала центром международной православной пропаганды, использующей власть и престиж рождающейся державы для своих целей» [7. С. 582]. Основной вывод Прицака сводился к тому, что политика московских князей и московской митрополии в отношении татарских ханств сильно различалась.

Роль идеологии во взаимоотношениях Российского государства и Казанского ханства была позднее изучена Я. Пеленски в его работе «Россия и Казань: завоевание и имперская идеология» [6]. В этом исследовании Я. Пеленски попытался построить модель формирующейся имперской идеологии Российского государства, для которой необходимость оправдания Казанского ханства стала своего рода «полигоном». Американский историк отказался от одностороннего взгляда на взаимоотношения Москвы и Казани, согласно которому они были постоянно враждебными или же, напротив, прагматичными. Пеленски отверг и взгляд Кинана о двух структурах, дипломатической и церковной, существовавших якобы в XV-XVI вв. в Российском государстве. По его мнению, «было бы заблуждением разделять отношения и цели церковной иерархии и видных светских деятелей нецерковного круга или же полагать, что в Московии XV-XVI вв. существовали две разные политические культуры» [6. С. 297]. Пеленски видит своего рода сотрудничество между этими двумя политическими структурами, которые и сделали возможными успехи Российского государства во внешней политике в XVI в. Основное внимание в своей работе американский историк уделил теоретическому обоснованию претензий Москвы на территорию Казанского ханства в источниках (среди них дипломатические источники, летописи, литературные произведения), которые составили в 1550-1560-е гг. основу идеологии Российского государства. Эту идеологию Пеленски обозначил как имперскую.

В своей работе американский историк выделил несколько групп таких обоснований. Во-первых, это группа исторических обоснований присоединения Казани к Российскому государству. Принятие Иваном IV в 1547 г. царского титула и покорение Казани в 1552 г. дали импульс к поиску таких обоснований. В 1550-1560-е гг., как пишет Пеленски, «русская имперская элита начала искать в истории объяснение своим успехам и достижениям, а также руководство для будущих политических действий» [6. С. 92]. Исторические обоснования прав на территорию характерны для средневековой идеологии. В случае с Казанским ханством московские идеологи использовали отрывки из «Повести временных лет», например известное описание восточнославянских племен и их соседей, которые были отобраны и переработаны. На их основе была выдвинута идея о том, что Казанское ханство «с древности» является владением Рюриковичей. Границы земель, население которых, согласно летописи, платило дань Рюриковичам, были расширены так, чтобы включить территорию Среднего и Нижнего Поволжья [6. С. 92].

Во-вторых, Пеленски выделяет группу династических притязаний московских правителей на Казань. В этом случае московские идеологи сформулировали две линии преемственности власти, которые касались Москвы 
и Казани. Российское государство и его правители рассматривались как преемники власти киевских и владимиро-суздальских князей. Казанское ханство, в свою очередь, мыслилось как преемник Волжской Булгарии и Золотой Орды. Далее было использовано летописное свидетельство о древнерусском походе 985 г. на Волжскую Булгарию. «Покорение» булгарских земель Владимиром I, якобы произошедшее в конце X в., позволило московским идеологам сделать вывод о том, что Иван IV просто возвратил себе вотчину своих предков [6. С. 99].

В-третьих, это та группа идей, которую Пеленски обозначил как «национальные обоснования» завоевания Казани. В этом случае Казанское ханство рассматривается как территория, исстари населенная русскими. Для национальных обоснований московские идеологи использовали миф о Саине Болгарском, который якобы изгнал из Среднего Поволжья русских. Такой же прием был использован и для обоснования российских претензий на Астрахань, которая была отождествлена с Тмутараканью. Таким образом, присоединение Казанского и Астраханского ханств было вплетено в процесс «собирания русских земель» [6. С. 104-135].

Особое место в ряду идеологических обоснований присоединения Казанского ханства к России у Пеленски занимают религиозные аргументы. Как указывает историк, рождающаяся государственная идеология «объединила религиозные обоснования во всеохватывающую провиденциальную интерпретацию русской истории» [5. С. 561]. В основу этой идеологии было положено представление о непрекращающемся конфликте между христианством и исламом, мирами «добра» и «зла». Взаимоотношения между Российским государством и Казанским ханством представали как еще одна сторона этого конфликта. Отсюда то большое значение, которое составители русских летописей придавали пророчествам и чудесам, связанным с покорением Казани. [6. С. 214-231].

Как отмечает Пеленски, присоединение Казанского ханства к России стало для официальной российской идеологии важным поводом к осмыслению места своего государства в мире. Результатом этого осмысления стал новый образ России как православной империи, влиятельной и могущественной, но окруженной враждебными соседями. Изменились и взгляды на историческую роль России, которую видели в присоединении народов и территорий. В результате присоединение Казанского ханства стало важнейшим моментом в истории формирования российской имперской идеологии [6. С. 304].

Таким образом, в середине XX в. в работах некоторых американских исследователей был поставлен вопрос о формировании российской политической культуры XVI в., ее монгольских и византийских истоках. Влияние этих двух традиций данные историки прослеживали, в частности, на примере внешней политики Российского государства. Многовековая политическая зависимость московских князей от Орды не могла не привести к восприятию ими норм и представлений кочевой или «степной» политической культуры. В результате Российское государство представало как государство-преемник Золотой Орды, для которого присоединение Казанского ханства было логичным завершением процесса «собирания ордынских земель». Так как Москва и ее правители были органичной частью степной политической культуры, в отношениях московских князей и татарских ханов доминировали взаимопонимание и прагматизм. С другой стороны, американские историки склонны 
прослеживать и влияние православной церкви на внешнюю политику Российского государства. На рубеже XV-XVI вв. это государство осмысливается в церковных кругах как православная империя, целью которой является распространение христианства. В этом случае Казанское ханство, как и прочие государства-преемники Золотой Орды, уже не могло рассматриваться как принадлежащее к единой с Российским государством политической культуре. Напротив, православные идеологи начали подчеркивать враждебность в отношении восточных исламских соседей Российского государства. Эта двойственность внешней политики московских правителей, проявившаяся в покорении Казани в 1552 г. и его последующем осмыслении, стала выводом историков Гарвардской школы. Наличие у России того времени двух моделей поведения в отношениях с восточными соседями (прагматичной и конфликтной) было объяснено неоднородностью самой российской государственности, в основе которой лежали монгольские и византийские традиции.

\section{Литература}

1. Рахимзянов Б.Р. Москва и Казань в средние века: герменевтика vs позитивизм? // Questio Rossica. 2019. T. 7, № 2. С. 669-681.

2. Cherniavsky M. Ivan the Terrible as Renaissance Prince. Slavic Review, 1968, vol. 27, pp. 195-211.

3. Cherniavsky M. Khan or Basileus: An Aspect of Russian Medieval Political Theory. Journal of the History of Ideas, 1959, vol. 20, pp. 459-476.

4. Keenan E. Muscovy and Kazan: Some Introductory Remarks in the Patterns of Steppe Diplomacy. Slavic Review, 1967, vol. 26, no. 4, pp. 548-558.

5. Pelenski J. Muscovite Imperial Claims to the Kazan Khanate. Slavic Review, 1967, vol. 26, no. 4, pp. 559-576.

6. Pelenski J. Russia and Kazan. Conquest and Imperial Ideology. The Hague-Paris, Mouton, 1974, $368 \mathrm{p}$.

7. Pritsak O. Moscow, the Golden Horde and the Kazan Khanate from the Policultural Point of View. Slavic Review, 1967, vol. 26, no. 4, pp. 577-583.

8. Sevcenco I. Moscow's Conquest of Kazan: Two Views Reconciled. Slavic Review, 1967, vol. 26, no. 4, pp. 541-547.

9. Toynbee A. Russia's Byzantine Heritage. Horizon, 1947, vol. 16, no. 91, pp. 82-95.

10. Wittfogel K. Russia and the East: A Comparison and Contrast. Slavic Review, 1963, vol. 22, pp. 627-642.

ПЕТУХОВ АЛЕКСАНДР ВАЛЕРИАНОВИЧ - каНДИДат исторИческИХ наук, ДОцент кафедры государственного и муниципального управления, Чебоксарский филиал Российской академии народного хозяйства и государственной службы при Президенте Российской Федерации, Россия, Чебоксары (alexpetkv@mail.ru; ORCID: https://orcid.org/0000-0002-5849-0482).

\section{Alexander V. PETUKHOV}

ACCESSION OF KAZAN KHANATE TO RUSSIA IN THE ASSESSMENTS OF AMERICAN HISTORIANS OF THE MIDDLE $20^{\text {th }}$ CENTURY

Key words: American historiography of the history of Russia, Kazan Khanate, Moscow-Kazan relations, political culture, state ideology, E. Keenan, Ya. Pelenski.

The article analyzes the views of American historians of the middle $20^{\text {th }}$ century on the problem of accession of Kazan Khanate to Russia. Studies on the history 
of Russian foreign policy have become relevant in the West with the beginning of the "cold war", the purpose of these studies was the need to identify the historical origins of "expansionist» foreign policy of the USSR and Russia. Searching the roots of "Russian expansionism", Western science of the middle $20^{\text {th }}$ century came to the conclusion about the non-European character of the Russian statehood, about Byzantine and Mongolian origins of the Russian state ideology, which substantiated its claim to world domination. Harvard University historians specializing in the history of Russia and the countries of Eastern Europe, in their works developed the concept of dual nature of the Russian state foreign policy ideology in the middle $16^{\text {th }}$ century. On the one hand, this ideology was based on the Mongolian political tradition inherited from the Golden Horde. On the other hand, Russian ideology was influenced by the Byzantine political tradition. In the works of E. Keenan and Ya. Pelenski's accession of Kazan Khanate to Russia was presented as the first embodiment in practice of Moscow rulers' claims to dominate in the political space of Eastern Europe. At the same time, Kazan's accession was a powerful impetus for the formation of the Russian state ideology, which was based on historical, dynastic, national and religious justifications for the claims to Kazan Khanate. Raised in the works of American historians, questions about Russian political culture and ideology of the $16^{\text {th }}$ century, their reflection in the sources and interpretation of ideas by modern researchers maintain their scientific relevance today.

\section{References}

1. Rakhimzyanov B.R. Moskva i Kazan: germenevtika vs positivism? [Moscow and Kazan in the Middle Ages: Hermeneutics vs Positivism?]. Questio Rossica, 2019, vol. 7, no. 2, pp. 669-681.

2. Cherniavsky M. Ivan the Terrible as Renaissance Prince. Slavic Review, 1968, vol. 27, pp. 195-211.

3. Cherniavsky M. Khan or Basileus: An Aspect of Russian Medieval Political Theory. Journal of the History of Ideas, 1959, vol. 20, pp. 459-476.

4. Keenan E. Muscovy and Kazan: Some Introductory Remarks in the Patterns of Steppe Diplomacy. Slavic Review, 1967, vol. 26, no. 4, pp. 548-558.

5. Pelenski J. Muscovite Imperial Claims to the Kazan Khanate. Slavic Review, 1967, vol. 26 , no. 4 , pp. 559-576.

6. Pelenski J. Russia and Kazan. Conquest and Imperial Ideology. The Hague-Paris, Mouton, 1974, $368 \mathrm{p}$.

7. Pritsak O. Moscow, the Golden Horde and the Kazan Khanate from the Policultural Point of View. Slavic Review, 1967, vol. 26, no. 4, pp. 577-583.

8. Sevcenco I. Moscow's Conquest of Kazan: Two Views Reconciled. Slavic Review, 1967, vol. 26, no. 4, pp. 541-547.

9. Toynbee A. Russia's Byzantine Heritage. Horizon, 1947, vol. 16, no. 91, pp. 82-95.

10. Wittfogel K. Russia and the East: A Comparison and Contrast. Slavic Review, 1963, vol. 22, pp. 627-642.

\footnotetext{
ALEXANDER V. PETUKHOV - Candidate of Historical Sciences, Assistant Professor, Department of State and Municipal Administration, Cheboksary Branch of the Russian Academy of National Economy and Public Administration Under the President of Russian Federation, Russia, Cheboksary (alexpetkv@mail.ru; ORCID: https://orcid.org/0000-0002-5849-0482).
}

Формат цитирования: Петухов А.В. Присоединение Казанского ханства к России в оценках американских историков середины XX века // Исторический поиск. - 2020. - Т.1, №3. - C.68-74. DOI: 10.47026/2712-9454-2020-1-3-68-74. 